Available online at www.sciencedirect.com

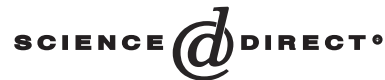

COLLOIDS

AND

\title{
Vegetable proteins and milk puddings
}

\author{
M.C. Nunes ${ }^{\mathrm{a}}$, P. Batista ${ }^{\mathrm{b}}$, A. Raymundo ${ }^{\mathrm{b}}$, M.M. Alves ${ }^{\mathrm{a}}$, I. Sousa ${ }^{\mathrm{c}, *}$ \\ ${ }^{\text {a }}$ Centro de Investigação em Reologia e Tecnologia Alimentar, Instituto Piaget-ISEIT de Mirandela, Avenida 25 de Abril, $5370-202$ \\ Mirandela, Portugal \\ ${ }^{\mathrm{b}}$ Centro de Investigação em Engenharia Alimentar e Biotecnologia, Instituto Piaget-ISEIT de Almada, Quinta da Arreinela de Cima, \\ 2800-305 Almada, Portugal

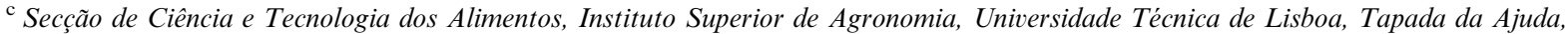 \\ 1349-017 Lisbon, Portugal
}

Received 19 August 2002; received in revised form 20 November 2002; accepted 4 February 2003

\begin{abstract}
In recent years, interest in animal free foods has increased tremendously due to factors like BSE crisis, rise of nutritionally dependent illnesses, like diabetes type II, cardiovascular and digestive diseases, along with ethic orientations of denying animal intakes of any kind. The use of proteins from leguminous seeds as an alternative to the animal proteins in dairy desserts was studied. Lupin, pea and soya protein isolates were used in combination with $\kappa-$ carrageenan, gellan and xanthan gum, in order to obtain a synergistic effect. Milk puddings were also produced for comparison. Texture studies suggested that mixed protein-polysaccharide systems, with vegetable proteins and $\kappa-$ carrageenan or gellan gum, would be good systems to develop vegetable gelled desserts. Rheological oscillatory measurements were carried out to clarify the kinetics of gelation and characterise the microstructure of the best performing products. Results from time sweep tests showed that formulations with gellan gum present an industrial advantage over formulations with $\kappa$-carrageenan, since the maturation time for gellan gels is of the order of 5-10 h compared with 4-6 days in the case of $\kappa$-carrageenan. All the mixed gels presented the typical weak gel structure; therefore, it was possible to perform steady-state measurements, which allowed the observation of a shear-thinning behaviour for all gels.
\end{abstract}

(C) 2003 Elsevier B.V. All rights reserved.

Keywords: Gellan gum; к-Carrageenan; Lupin; Pea; Rheology; Soy; Texture; Dessert; Xanthan gum

\section{Introduction}

The food industry is moving toward developing new products by using innovative ingredients with

\footnotetext{
* Corresponding author. Tel.: +351-21-365-3543; fax: + 351-21-365-3200.

E-mail address: isabelsousa@isa.utl.pt (I. Sousa).
}

health benefits. It is clear that the use of globular proteins from legumes can be a very interesting alternative to animal based food [1]. Besides for nutritional properties, proteins from leguminous seeds have gained increasing importance because they are also used to provide desired functional properties, including gelling, emulsifying, fat-absorbing and water binding properties $[2,3]$. 
To obtain such functional properties, hydrocolloids can also be used and a synergistic effect can be observed [4]. Protein-polysaccharide mixed systems have been extensively studied and widely used in the food industry in the last decades, because the biopolymers interactions are of great importance to develop products with specific textures [5,6].

Soy protein is extensively used as a food ingredient [3,7]. Previous studies at our laboratory had shown the high potential of white lupin protein as foam stabilising agent [8] and its capacity to produce and stabilise food emulsions [9-11]. Recent works, about the similarities between lupin and soya proteins in terms of physical characteristics [12,13] and studies on functional properties of pea protein $[14,15]$, led us to study the possibility of using lupin and pea proteins to create new food products with a gel like structure.

There already exist in the market, some substitutes for dairy desserts produced with soya protein, but their texture/consistency is still very poor, which is a major obstacle in terms of high quality standards. In a consumer-oriented market, besides the healthy aspects, food products should have an attractive image and a good taste. The objective of our work is, therefore, to study the replacement of milk by proteins extracted from lupin, pea and soya, in combination with $\kappa$ carrageenan, gellan or xanthan gum, in order to select a protein-polysaccharide system to produce vegetable gels, with mechanical properties similar to those of the dairy gelled desserts. A reference dairy dessert was prepared using milk, starch and $\kappa$-carrageenan. The best protein-polysaccharide systems were selected on the basis of texture characteristics. Previously, we characterised some commercial dairy desserts in order to define a target and the range of variation of the most representative physico-chemical properties [16].

Since the structure evolution of the gels and their final mechanical properties are very important aspects, cooling and maturation kinetics of the best performing products were monitored in a controlled stress rheometer by means of oscillatory rheological measurements. It was also possible to perform steady-state measurements in order to determine the differences in flow behaviour of the protein-polysaccharide gels.

\section{Materials and methods}

\subsection{Materials}

Three protein isolates: pea isolate (Pisane, Cosucra, Belgium), lupin isolate (LupiE, Fraunhofer Inst., Germany) and soya isolate (S974, ADM, Netherlands) were used. Four polysaccharides were used: Xanthan gum (Satiaxane CX910, Degussa, France), $\kappa$-carrageenan (Satiagel AMP45, Degussa), low-acyl gellan gum (Kelcogel F, Kelco, UK) and native maize starch (Vitena A, Copan, Portugal). These materials were all kindly provided by the respective manufacturers. Sucrose and milk were of commercial grade.

\subsection{Methods}

\subsubsection{Preparation of gels}

Four desserts (with milk, pea, lupin or soya proteins) were prepared using each of the three gums mentioned. The formulations contained demineralised water, milk or vegetable isolates at a level that provides a protein content of $2 \%(\mathrm{w} / \mathrm{w})$. Gellan gum and $\kappa$-carrageenan were used at a level of $0.15 \%(\mathrm{w} / \mathrm{w})$ and xanthan gum at $0.20 \%(\mathrm{w} / \mathrm{w})$. The other ingredients, starch and sucrose, were used at levels of 2.5 and $15 \%$ (w/w), respectively.

Suspensions were made by mixing the milk and/ or water with the dry ingredients, under magnetic stirring $(1 \mathrm{~h})$ at room temperature. The suspensions were heated-up to boiling for $3 \mathrm{~min}$ and, immediately after, poured into $6 \mathrm{~cm}$ diameter cylindrical containers filled up to $3.5 \mathrm{~cm}$ height, and allowed to set at a temperature of $5-7{ }^{\circ} \mathrm{C}$, in the refrigerator, for texture analysis. For rheological measurements, the samples were immediately poured into the rheometer-measuring system.

\subsubsection{Texture characterisation}

Texture parameters were determined from the texture profile analysis using a TAX-T2i (Stable Micro Systems, UK) texturometer with a $25 \mathrm{~mm}$ diameter cylindrical probe $(10 \mathrm{~mm}$ of penetration, 
$5 \mathrm{~s}$ of waiting time and $2 \mathrm{~mm} / \mathrm{s}$ of crosshead speed). The experiments were carried out $24 \mathrm{~h}$ after preparation of the desserts with gellan or xanthan and after 8 days for those with $\kappa$-carrageenan, in order to allow full maturation of the gels. Before performing any measurements, gels were allowed to equilibrate at $20{ }^{\circ} \mathrm{C}$ for approximately $3 \mathrm{~h}$ in a temperature-controlled room. Results for each sample were determined at least three times.

Firmness $\left(\mathrm{N} / \mathrm{m}^{2}\right)$ was considered as the maximum resistance to the penetration of the probe and was calculated as the height of the force peak during the first compression cycle, divided by the probe contact area. Fracturability was defined as the force at the significant break in the curve on the first compression, divided by the probe contact area. Adhesiveness represented the work necessary to pull the probe away from the sample and was recorded as the negative force area of the first compression [17].

\subsubsection{Rheological measurements}

Rheological measurements were performed using a controlled-stress rheometer (RS-150, Haake, Germany). Since the initial consistency of samples varied, different sensors had to be used: cone-plate geometry $\left(35 \mathrm{~mm}, 2^{\circ}\right.$ ) for $\kappa$-carrageenan gels and a serrated parallel-plate sensor $(35,1$ mm gap) for gellan gels, in order to avoid slip [18]. The gels were placed in the rheometer-measuring device at 65 or $40{ }^{\circ} \mathrm{C}$, respectively, for $\kappa$-carrageenan and gellan, and cooled down to $5^{\circ} \mathrm{C}$ at $0.6{ }^{\circ} \mathrm{C} /$ min. Development of structure was studied by oscillatory measurements, at a constant frequency of $1 \mathrm{~Hz}(6.28 \mathrm{rad} / \mathrm{s})$. After this period, without disturbing the sample, frequency sweeps were conducted at $5{ }^{\circ} \mathrm{C}$, with oscillation frequencies ranging from 0.01 to $115.6 \mathrm{rad} / \mathrm{s}$. After the dynamic measurements, which were performed inside the linear viscoelastic region, steady-state flow measurements were carried out at $5{ }^{\circ} \mathrm{C}$, using a logarithmic ramp of stresses increasing in $30 \mathrm{~min}$ from 0.1 to $2000 \mathrm{~Pa}$. The samples were covered with a layer of paraffin oil to prevent moisture loss.

\section{Results and discussion}

\subsection{Texture results}

The firmness and adhesiveness values, obtained for the desserts studied, are shown in Fig. 1. Fracturability values are not presented as a figure, because only the gels with gellan gum showed this characteristic. One-Way ANOVA was used to compare texture parameters of the gels.

The milk/ $\kappa$-carrageenan gel showed higher firmness than the vegetable ones. In fact, the gelation phenomenon involves a highly specific interaction
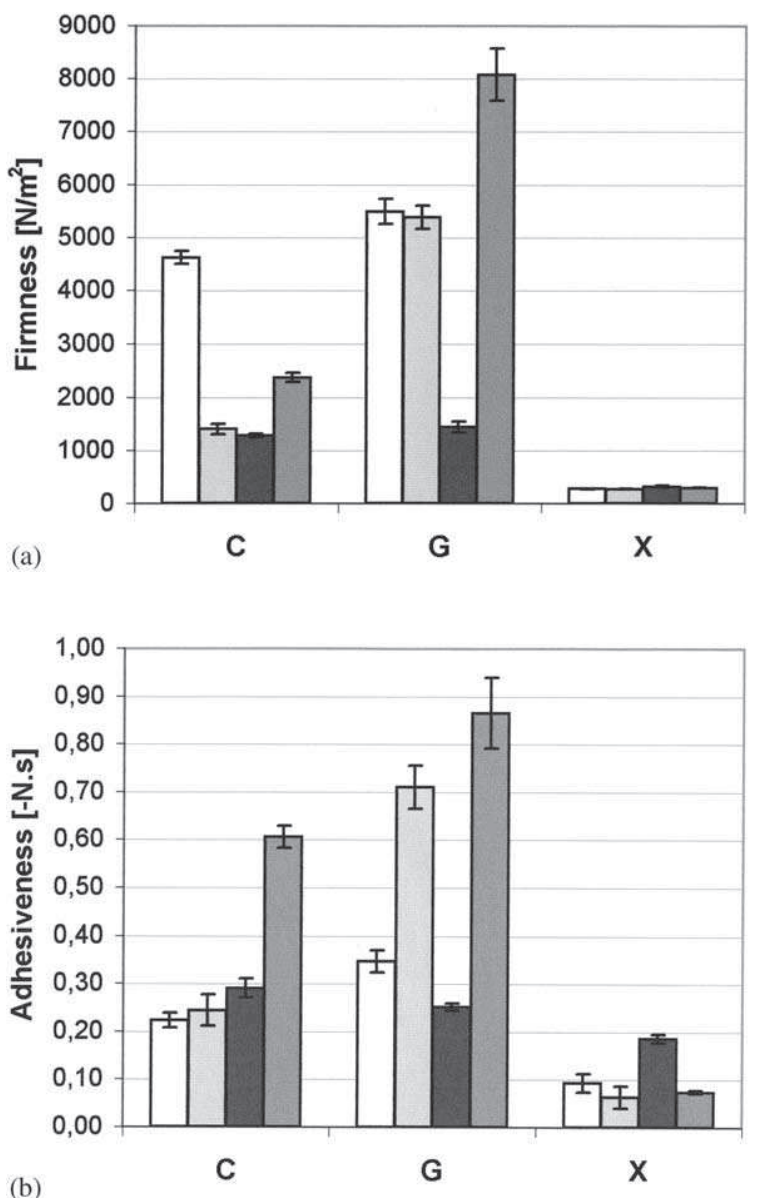

Fig. 1. Firmness (A) and adhesiveness (B) values of proteinpolysaccharide gels with milk protein (white bar), pea protein (light gray bar), lupin protein (black bar) and soya protein (dark gray bar). C ( $\kappa$-carrageenan); G (gellan gum); X (xanthan gum). 
between $\kappa$-carrageenan and $\kappa$-casein with formation of an electrostatic bridge between these two molecules [19]. As referred in literature, potassium is the stronger gelation-inducer of $\kappa$-carrageenan gels, whereas less pronounced effects are obtained with sodium and calcium ions $[19,20]$. The ion content of the protein isolates was enough to promote $\kappa$-carrageenan gelation, because no extra ions were supplied. The gel that showed the closest value of firmness to that of the milk pudding was the soya/carrageenan dessert. Nevertheless, firmness values of all the vegetable gels produced are similar to those obtained for commercially available desserts [16], for which firmness varied from 721 to $4222 \mathrm{~N} / \mathrm{m}^{2}$. Adhesiveness values of all the gels were lower compared with commercial desserts $(0.4-2.7 \mathrm{~N} \mathrm{~s})$.

When using gellan gum, a desirable texture could only be obtained with milk protein. This must be related to the fact that gellan gum forms very weak gels in the absence of ions, particularly calcium or magnesium. Monovalent ions, such as potassium or sodium can also be used, but much higher concentrations are required [21]. Therefore, we provided an extra source of calcium, with the addition of $0.12 \% \quad(\mathrm{w} / \mathrm{w})$ dehydrated calcium chloride, similar to the milk content, to obtain gels with the vegetable protein isolates. Although it is known that gellan gum forms brittle gels showing syneresis $[22,23]$, the use of vegetable proteins and starch in our formulations reduced substantially this negative characteristic. The firmness value of the pea/gellan gel is not significantly different $(P<0.05)$ from that of the milk/gellan dessert. The lupin/gellan gel showed the lowest values for the textural parameters, even though its firmness is inside the range of variation of this characteristic for commercial desserts. Surprisingly, the soya/gellan gel showed the highest textural parameters. Formulations with milk, pea and soya proteins showed fracturability values of 5410,5414 and $7900 \mathrm{~N} / \mathrm{m}^{2}$, respectively (values of milk and pea gels are not significantly different at $P<0.05$ ), but lupin/gellan gel did not showed fracturability.

The mixed systems protein/xanthan gum did not have a desirable texture. This can be explained by the fact that xanthan gum is a non-gelling poly- saccharide, and apparently no synergistic effect occurs for these experimental conditions.

These texture studies suggested that mixed protein-polysaccharide systems with pea, lupin or soy and $\kappa$-carrageenan or gellan gum may be good systems to develop vegetable gelled desserts.

\subsection{Rheological results}

It was not possible to detect the sol-gel transition for the protein/ $/$-carrageenan and protein/ gellan gum systems. This transition occurred at high temperatures. It was practically impossible to bring these mixtures in the measuring device at the
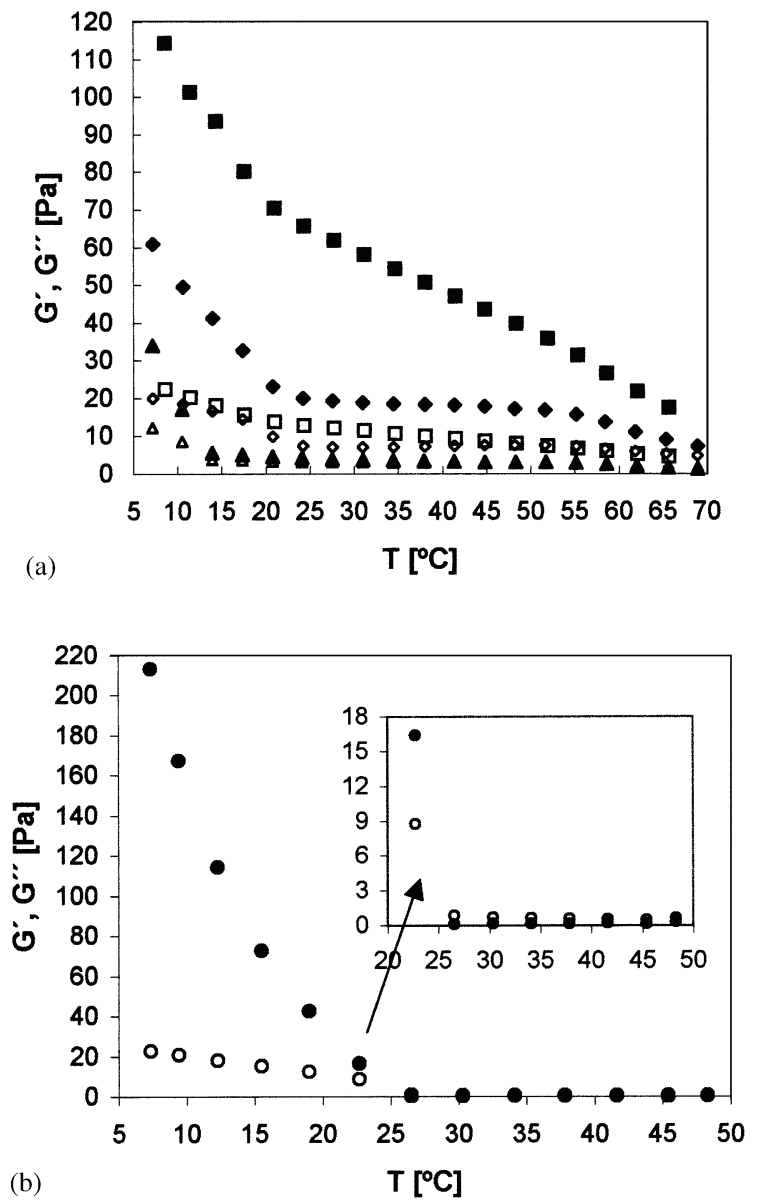

Fig. 2. Temperature sweeps of the vegetable proteins/ $/$-carrageenan systems (A) and of a $1.2 \% \kappa$-carrageenan solution (B). Pea $(\checkmark)$; lupin ( $)$ ); soya $(\boldsymbol{\square}) . \mathrm{G}^{\prime}$ (filled symbol); $\mathrm{G}^{\prime \prime}$ (open symbol). 
required temperatures. For vegetable proteins/ $/$ carrageenan gels (Fig. 2A), the change in $\mathrm{G}^{\prime}$ and $\mathrm{G}^{\prime \prime}$ slopes with increasing temperature was clearly observed. The reason for this is probably due to the gelation mechanism of $\kappa$-carrageenan. The gelling temperature of a model $1.2 \% \kappa$-carrageenan solution, prepared only with demineralised water and gum under the same processing conditions, is shown in Fig. 2B. The cooling curve of the milk/א-carrageenan system shows only one region (Fig. 3), probably due to the already mentioned interaction between carrageenan and $\kappa$-casein [19].

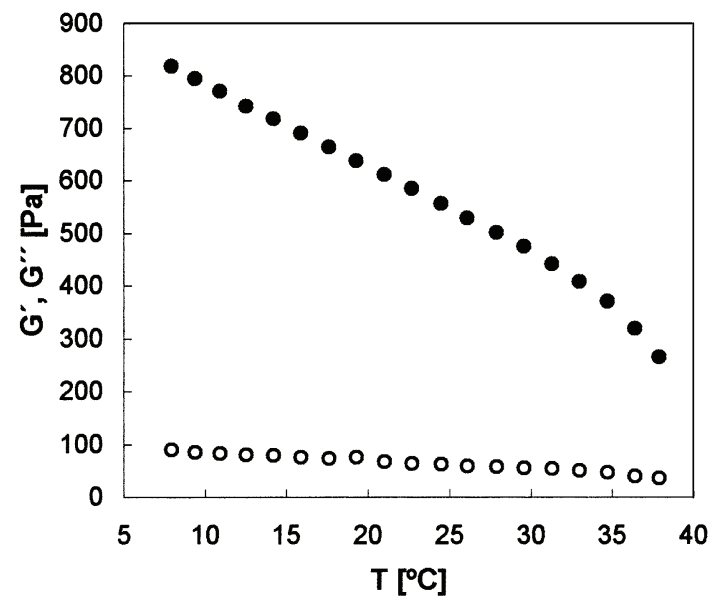

Fig. 3. Temperature sweep of the milk/k-carrageenan system. $\mathrm{G}^{\prime}$ (filled symbol); $\mathrm{G}^{\prime \prime}$ (open symbol).

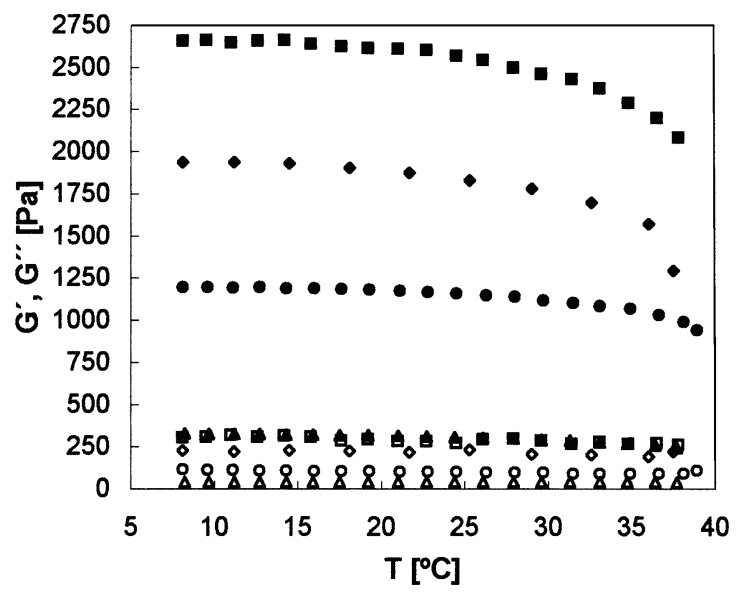

Fig. 4. Temperature sweeps of the protein/gellan gum systems.

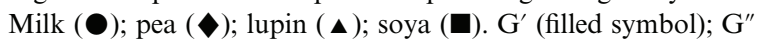
(open symbol).
A similar feature was observed for the protein/ gellan gum systems (Fig. 4). In gellan gum gelation, a rapid formation of a strong gel occurs $[24,25]$.

The maturation kinetics of protein/א-carrageenan (Fig. 5A, B) and protein/gellan gum (Fig. 6) gels, were monitored through the evolution with time of the storage $\left(\mathrm{G}^{\prime}\right)$ and loss $\left(\mathrm{G}^{\prime \prime}\right)$ moduli at $5{ }^{\circ} \mathrm{C}$. The steady value of $\mathrm{G}^{\prime}$ where the gel reaches a stable and fully developed structure can be defined as the $G_{e q}^{\prime}$, i.e. the value of $G^{\prime}$ at equilibrium when time is long enough [26],
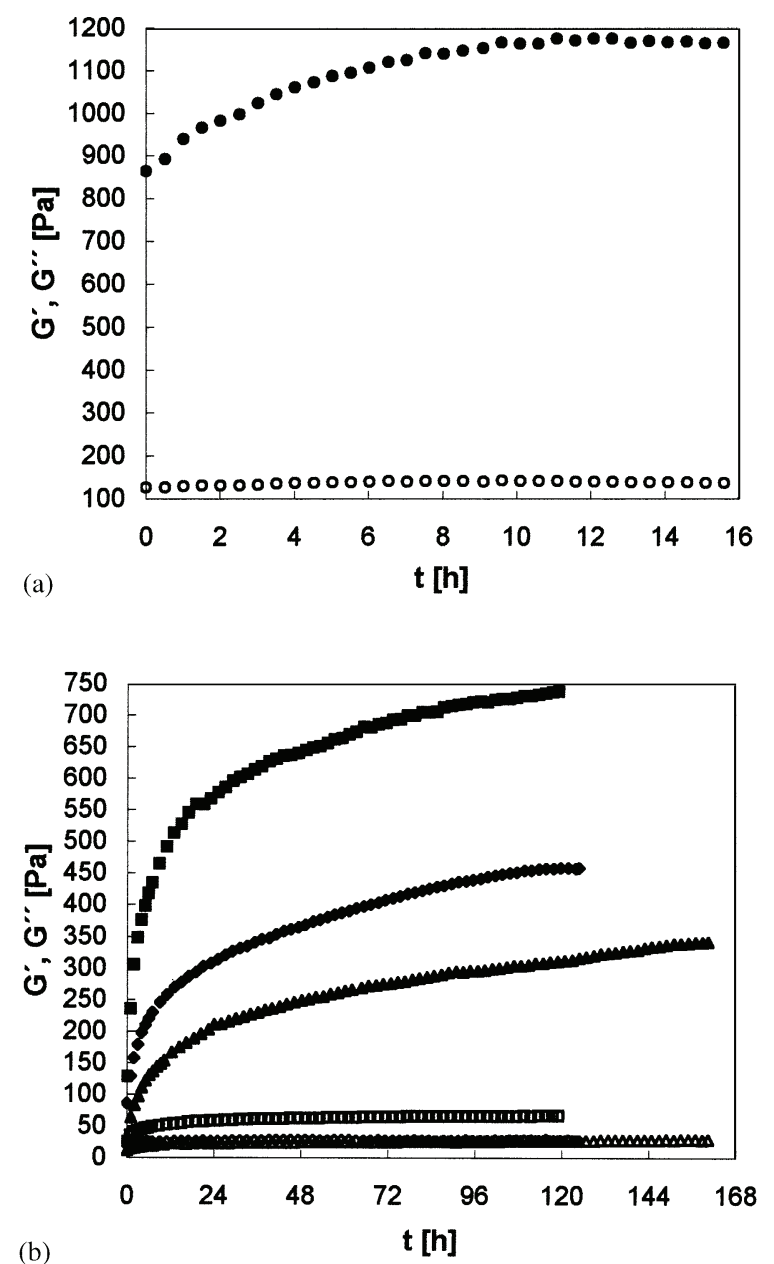

Fig. 5. Time sweeps of the milk/א-carrageenan (A) and vegetable proteins/ $/$-carrageenan (B) gels at $5{ }^{\circ} \mathrm{C}$. Milk (O); pea ( $)$; lupin ( $\mathbf{\Delta}$ ); soya $(\boldsymbol{\square})$. $\mathrm{G}^{\prime}$ (filled symbol); $\mathrm{G}^{\prime \prime}$ (open symbol). 


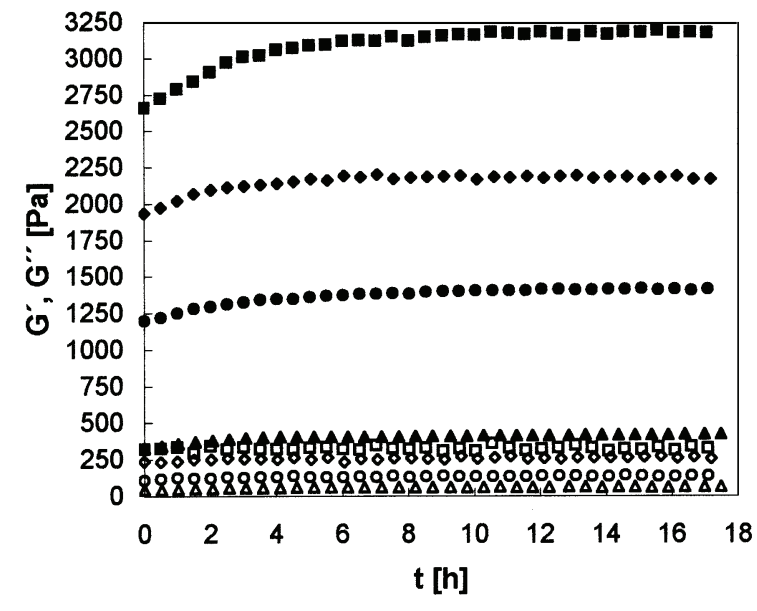

Fig. 6. Time sweeps of the proteins/gellan gum gels at $5^{\circ} \mathrm{C}$.

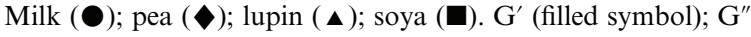
(open symbol).

$G_{\text {eq }}^{\prime}=\lim _{\mathrm{t} \rightarrow \infty} G^{\prime}(\mathrm{t})$

This can be written as:

$G_{\text {eq }}^{\prime}=\lim _{\overline{\mathrm{t}} \rightarrow 0} G^{\prime}(\mathrm{t})$

Transforming Figs. 5 and 6 accordingly to be fitted to an exponential decay of the form:

$G^{\prime}(\mathrm{t})=\mathrm{y}_{0}+\mathrm{A}_{1} \mathrm{e}^{\frac{-\mathrm{k}}{\mathrm{b}_{1}}}+\mathrm{A}_{2} \mathrm{e}^{\frac{-\mathrm{k}}{\mathrm{b}_{2}}}$

where $\mathrm{y}_{0}, \mathrm{~A}_{1}, \mathrm{~A}_{2}, \mathrm{~b}_{1}$ and $\mathrm{b}_{2}$ are the equation parameters and $\mathrm{k}$ is the reciprocal time, i.e. $1 / \mathrm{t}$.
From Eq. (2) $\mathrm{G}_{\mathrm{eq}}^{\prime}$ can be calculated. These parameters can be seen on Table 1 for gels studied. Eq. (3) gives values of $\mathrm{G}^{\prime}$ for different time values. For the $\kappa$-carrageenan gel systems a value of $\mathrm{G}^{\prime}$ $(93 \%)$ close to $\mathrm{G}_{\mathrm{eq}}^{\prime}$ was reached after $10 \mathrm{~h}$ of maturation for milk. However, when vegetable proteins were used, after $100 \mathrm{~h}$ of gel maturation the values of $\mathrm{G}^{\prime}$ were only at 86,77 and $70 \%$ of $\mathrm{G}_{\text {eq }}^{\prime}$ for soy, pea and lupin, respectively. These results are showing higher difficulties for the vegetable proteins to form a gel structure with $\kappa$ carrageenan compared with milk proteins.

In the case of gellan gum systems with milk as with vegetable proteins, after $10 \mathrm{~h}$ of gel maturation time values of $\mathrm{G}^{\prime}$ were close $(>97 \%)$ to $\mathrm{G}_{\mathrm{eq}}^{\prime}$. This means that fully developed structures were reached for these mixed gels since differences between calculated $\mathrm{G}_{\mathrm{eq}}^{\prime}$ and $\mathrm{G}^{\prime}$ were below the experimental error. With gellan gum vegetable proteins give a stable gel structure much earlier than with $\kappa$-carrageenan which can be seen as an advantage from an industrial point of view.

Fig. 7 shows the frequency spectra of these structures at $5{ }^{\circ} \mathrm{C}$. All the gels analysed presented a typical weak gel-like response, i.e. $\mathrm{G}^{\prime}$ is always higher than $\mathrm{G}^{\prime \prime}$ (at about one decade) with both moduli slightly frequency dependent. The linear viscoelastic data for the milk and soy/א-carrageenan gels are qualitatively similar, with values of $\mathrm{G}^{\prime}$ at $1 \mathrm{~Hz}$ of 1154 and $739 \mathrm{~Pa}$, respectively, and higher than those of pea and lupin/К-carrageenan

Table 1

Parameters of exponential decay (Eq. (3)) with the respective statistics and calculate $\mathrm{G}_{\mathrm{eq}}^{\prime}$ (Eq. (2)) for the gel systems with $\kappa$ carrageenan (a) and gellan gum (b)

\begin{tabular}{llllllllll}
\hline Protein & $\mathrm{y}_{0}$ & $\mathrm{~A}_{1}$ & $\mathrm{~b}_{1}$ & $\mathrm{~A}_{2}$ & $\mathrm{~b}_{2}$ & $\chi^{2}$ & $\mathrm{G}_{\mathrm{eq}}^{\prime}(\mathrm{Pa})$ & $\mathrm{G}_{\mathrm{t}}^{\prime}(\mathrm{Pa})$ & $\mathrm{G}_{10 \mathrm{~h}}^{\prime}(\mathrm{Pa})$ \\
\hline$(a)$ & & & & & & & & & \\
$\mathrm{M}$ & 894.9 & 100.0 & 0.569 & 240.6 & 0.300 & 111.7 & 1236 & $1151(10 \mathrm{~h})$ & \\
$\mathrm{P}$ & 88.9 & 229.1 & 0.257 & 256.2 & 0.015 & 10.2 & 574 & $440(100 \mathrm{~h})$ & \\
$\mathrm{L}$ & 74.0 & 180.1 & 0.009 & 175.8 & 0.137 & 14.3 & 430 & $300(100 \mathrm{~h})$ & \\
$\mathrm{S}$ & 239.5 & 231.1 & 0.017 & 366.7 & 0.248 & 26.5 & 837 & $721(100 \mathrm{~h})$ & 1397 \\
$(b)$ & & & & & & & & & 2177 \\
$\mathrm{M}$ & 1220.3 & 149.1 & 0.531 & 70.9 & 0.350 & 20.8 & 1440 & & 415 \\
$\mathrm{P}$ & 1914.8 & 198.3 & 0.996 & 88.6 & 1.460 & 175.2 & 2202 & & 3151 \\
$\mathrm{~L}$ & 328.7 & 49.1 & 0.559 & 49.5 & 1.200 & 5.8 & 427 & & \\
$\mathrm{~S}$ & 2621.3 & 507.2 & 0.528 & 112.1 & 5.500 & 180.4 & 3241 & & \\
\hline
\end{tabular}

M (milk); P (pea); L (lupin); S (soya). 

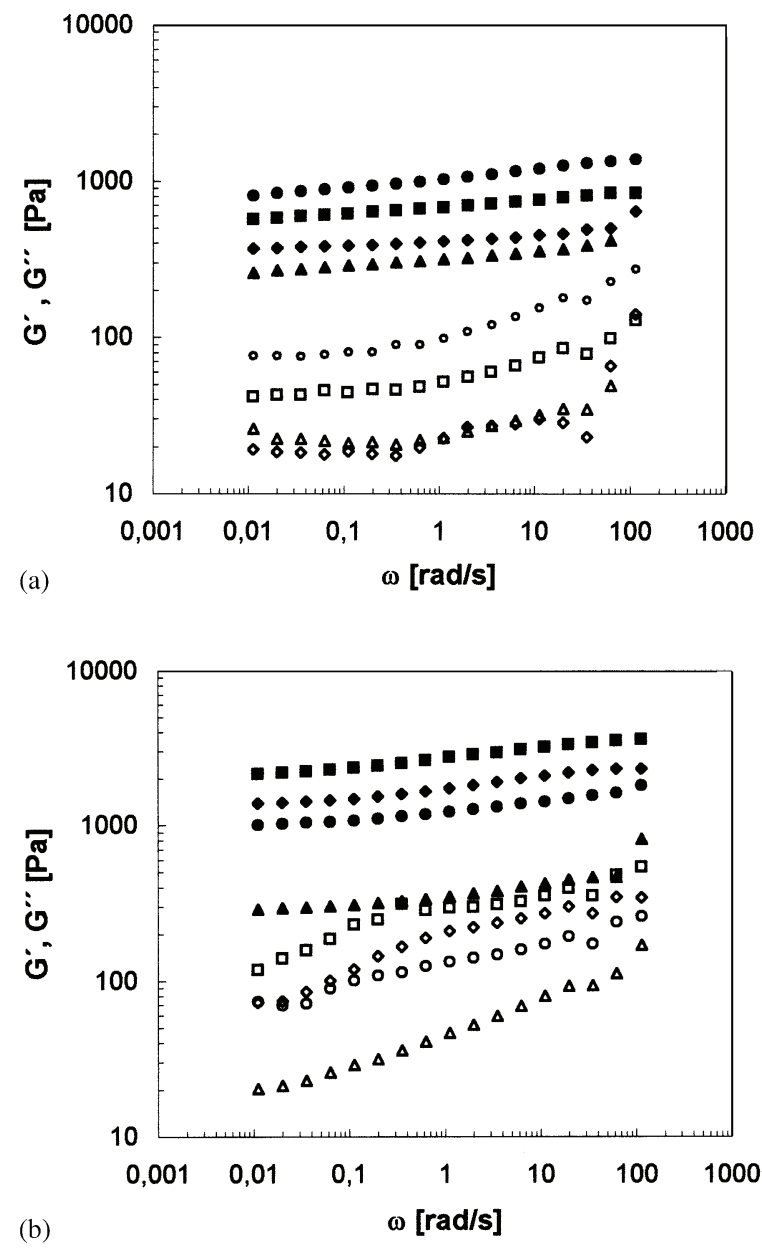

Fig. 7. Frequency sweeps of the protein/א-carrageenan (A) and protein/gellan (B) gels at $5{ }^{\circ} \mathrm{C}$. Milk $(\bullet)$; pea $(\diamond)$; lupin $(\boldsymbol{\Delta})$; soya (ם). G' (filled symbol); $\mathrm{G}^{\prime \prime}$ (open symbol).

gels, of 439 and $343 \mathrm{~Pa}$. The protein/gellan gum spectra (Fig. 7B) are indicative for more structured materials compared with $\kappa$-carrageenan gels, with $\mathrm{G}^{\prime}(1 \mathrm{~Hz})$ ranging from $1369 \mathrm{~Pa}$ in the case of milk, to $3070 \mathrm{~Pa}$ for soya gel. The exception was the lupin/gellan gum gel, which showed a mechanical behaviour similar to the lupin/א-carrageenan gel, with a $\mathrm{G}^{\prime}(1 \mathrm{~Hz})$ of $401 \mathrm{~Pa}$, and $\mathrm{G}^{\prime \prime}$ being frequency dependent, i.e. this gel shows a more viscous behaviour at longer time scales $(t=1 / \omega)$.

All the weak gels studied under steady shear conditions showed similar flow curves, exhibiting a strong shear-thinning behaviour (Fig. 8). These complex materials, with an internal structure as a network gel, can be seen as soft solids. However, they show a true value of viscosity $\eta_{0}$, at very low shear. These values are very high $\left(10^{5} \mathrm{~Pa} \mathrm{~s}\right)$ and fall suddenly, when gel structure breaks, five orders of magnitude, to a much fluid behaviour. This type of flow was recently well described by Barnes [27].

The flow curves could satisfactory be fitted by the Carreau equation [28]:

$\eta_{\text {ap }}=\eta_{\infty}+\left(\eta_{0}-\eta_{\infty}\right) /\left[1+\left(\frac{\dot{\gamma}}{\dot{\gamma}_{c}}\right)^{2}\right]^{\mathrm{s}}$

where $\eta_{\text {ap }}$ is the apparent viscosity of the system measured at the shear rate $\dot{\gamma}, \eta_{0}$ is the limiting viscosity of the initial Newtonian plateau, $\eta_{\infty}$ the limiting Newtonian viscosity at higher shear rates,
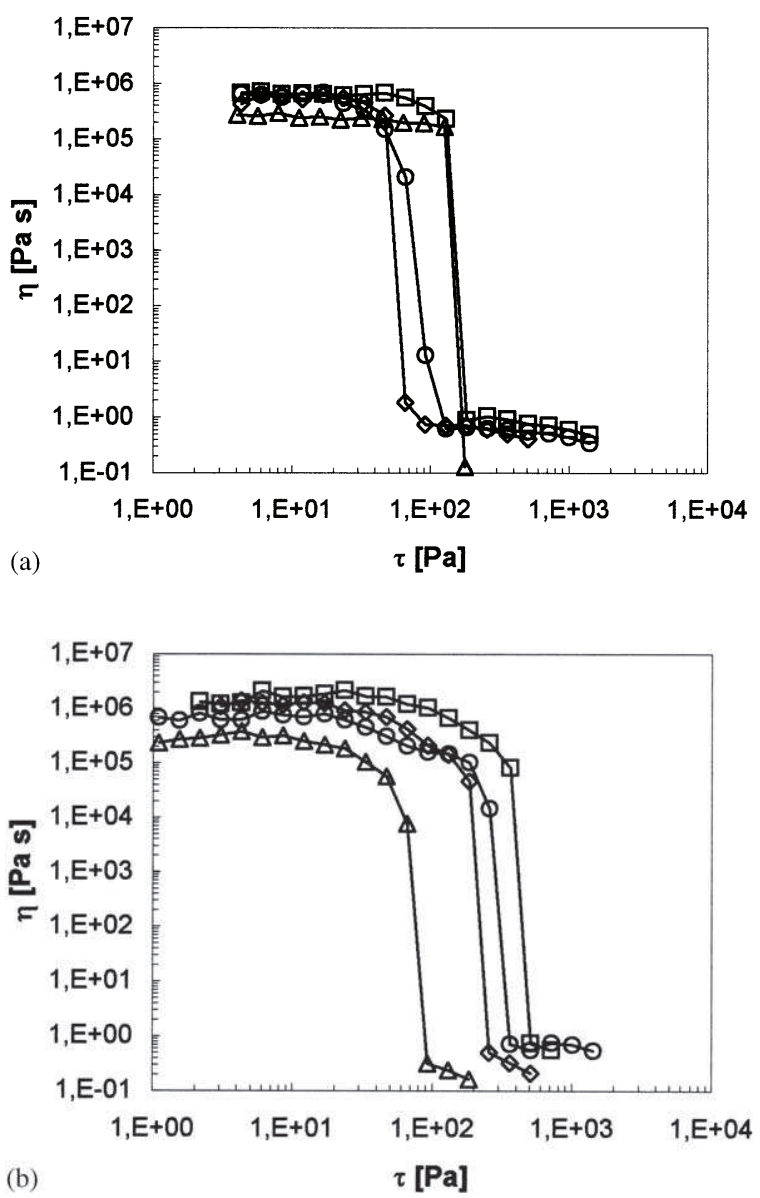

Fig. 8. Steady-state flow curves of the protein/к-carrageenan (A) and protein/gellan gum (B) gels at $5{ }^{\circ} \mathrm{C}$. Milk $(\bullet)$; pea ( $)$; lupin ( $\mathbf{\Lambda})$; soya $(\mathbf{\square})$. 
Table 2

Magnitudes of the parameters from Carreau model, for protein-polysaccharide systems with $\kappa$-carrageenan (a) and gellan gum (b)

\begin{tabular}{|c|c|c|c|c|c|}
\hline Protein & $\eta_{0}(\mathrm{~Pa} \mathrm{~s})$ & $\eta_{\infty}(\mathrm{Pa} \mathrm{s})$ & $\dot{\gamma}_{\mathrm{c}}(1 / \mathrm{s})$ & $\mathrm{s}$ & $\operatorname{MRD}^{\mathrm{a}}(\%)$ \\
\hline \multicolumn{6}{|l|}{ (a) } \\
\hline $\mathrm{M}$ & 680000 & 0.418 & $9.27 \times 10^{-5}$ & 0.49 & 8.2 \\
\hline $\mathrm{P}$ & 639806 & 0.450 & $1.51 \times 10^{-4}$ & 0.53 & 8.5 \\
\hline $\mathrm{L}$ & 269994 & - & $1.17 \times 10^{-3}$ & 0.44 & 5.2 \\
\hline $\mathrm{S}$ & 690000 & 0.567 & $3.12 \times 10^{-4}$ & 0.52 & 4.4 \\
\hline \multicolumn{6}{|l|}{ (b) } \\
\hline $\mathrm{M}$ & 640000 & 0.476 & $3.51 \times 10^{-4}$ & 0.50 & 11.5 \\
\hline $\mathrm{P}$ & 1260000 & 0.103 & $1.06 \times 10^{-4}$ & 0.48 & 11.6 \\
\hline $\mathrm{L}$ & 365000 & 0.080 & $1.41 \times 10^{-4}$ & 0.48 & 9.1 \\
\hline $\mathrm{S}$ & 1711805 & 0.158 & $1.68 \times 10^{-4}$ & 0.48 & 10.9 \\
\hline
\end{tabular}

M (milk); P (pea); L (lupin); S (soya).

${ }^{a}$ MRD, mean relative deviation.

$\dot{\gamma}_{c}$ is a critical shear rate for onset of the shearthinning behaviour and $\mathrm{s}$ is a parameter related to the slope of this shear thinning region. The magnitudes of the parameters obtained for all of the systems studied are presented in Table 2, and as may be observed, the differences are more pronounced for the limiting viscosity at high shear rates. The $\eta_{0}$ values of the mixed $\kappa$-carrageenan gels are of the order of $10^{5} \mathrm{~Pa} \mathrm{~s}$, with lupin/ $/$ carrageenan gel showing the lower value. Milk and lupin gels with gellan gum showed $\eta_{0}$ values of the order of $10^{5} \mathrm{~Pa} \mathrm{~s}$, as well, but soya and pea gels have higher $\eta_{0}$ values, of the order of $10^{6} \mathrm{~Pa} \mathrm{~s}$.

Considering both texture and rheological measurements, it is possible to conclude that the results obtained from rheological tests are in close agreement with those found from texture characterisation of the same gels.

\section{Conclusions}

Texture characterisation suggested that protein-polysaccharide gels with vegetable proteins and $\kappa$-carrageenan or gellan gum would be good systems to develop gelled desserts, in which animal proteins are fully replaced, with subsequent multiple advantages from the economic and health-hazard points of view.

From the rheological studies it was seen that all the mixed gels present the typical weak gel structure and a shear-thinning behaviour. Results from time sweep tests allowed the conclusion that formulations with gellan gum present an industrial advantage over formulations with $\kappa$-carrageenan, since the maturation time for gellan gels is of the order of $10 \mathrm{~h}$ compared with about 1 week in the case of $\kappa$-carrageenan. However, due to the already mentioned fact that gellan gum forms brittle gels with fracturability, further work will be necessary to evaluate these desserts on the basis of sensory characterisation, relevant for consumer acceptance.

It is clear that the gelation ability of mixed systems with globular proteins from legumes and polysaccharides can be an interesting alternative to gelled milk puddings. However, besides the present data obtained only from rheological measurements, it is obviously necessary to take into account information from other methods, in order to understand the interaction phenomena of these proteins with the polysaccharides. Detailed study on all variables involved in the gelation mechanism, such as time/temperature effects, hydrocolloids content, $\mathrm{pH}$ conditions and salt additions need to be continued.

\section{Acknowledgements}

This work is a part of a research project, sponsored by Fundação para a Ciência e a Tecnologia (Reference POCTI/AGR/38251/2001). We gratefully acknowledge Professor João Maia 
(Department of Polymer Engineering, University of Minho) for the fruitful discussions of the results.

\section{References}

[1] H. Bollinger, Food Marketing and Technology 15 (2001) 10.

[2] J.E. Kinsella, Journal of American Oil Chemical Society 56 (1979) 242.

[3] K. Liu, Food Technology 54 (2000) 46.

[4] V.B. Tolstoguzov, Food Hydrocolloids 4 (1991) 429

[5] V.B. Tolstoguzov, in: S.E. Hill, D.A. Ledward, J.R. Mitchell (Eds.), Functional Properties of Food Macromolecules, Aspen, USA, 1998.

[6] E.E. Braudo, in: P.A. Williams, G.O. Philips (Eds.), Gums and Stabilisers for the Food Industry, The Royal Society of Chemistry, Cambridge, 1998.

[7] C.V. Morr, Journal of American Oil Chemical Society 67 (1990) 265.

[8] A. Raymundo, J. Empis, I. Sousa, Zeitschrift fur Lebensm. Unters. Forsch. 207 (1998) 91.

[9] J. Franco, A. Raymundo, I. Sousa, C. Gallegos, Journal of Agricultural Food Chemistry 46 (1998) 3109.

[10] A. Raymundo, J. Franco, C. Gallegos, J. Empis, I. Sousa, Nahrung 42 (1998) 220.

[11] A. Raymundo, J. Franco, P. Partal, I. Sousa, C. Gallegos, Journal of Surfactants and Detergents 2 (1999) 545.

[12] I.M.N. Sousa, P.J. Morgan, J.R. Mitchell, S.E. Harding, S.E. Hill, Journal of Agricultural Food Chemistry 44 (1996) 3018 .

[13] A. Kiosseoglou, G. Doxastakis, S. Alevisopoulos, S. Kasapis, International Journal of Food Science and Technology 34 (1999) 253.
[14] P.S. Bora, C.J. Brekke, J.R. Powers, Journal of Food Science 59 (1994) 594.

[15] R. Ipsen, Carbohydrate Polymers 28 (1995) 337.

[16] P. Batista, M.C. Nunes, I. Sousa, in: F. Martinez Boza, A. Guerrero, P. Partal, J. Franco, J. Munoz (Eds.), Progress in Rheology: Theory and Applications, Publicaciones Digitales, Spain, 2002.

[17] M. Bourne, Food Texture and Viscosity: Concept and Measurement, Academic Press, UK, 2002.

[18] H.A. Barnes, Journal of Non-Newtonian Fluid Mechanics 56 (1995) 221

[19] N.F. Stanley, in: P. Harris (Ed.), Food Gels, Elsevier, London, 1990.

[20] V.J. Morris, in: J.R. Mitchell, D.A. Ledward (Eds.), Functional Properties of Food Macromolecules, Elsevier, London, 1986.

[21] G.R. Sanderson, in: P. Harris (Ed.), Food Gels, Elsevier, London, 1990.

[22] G.R. Sanderson, U.L. Bell, D.R. Burgum, R.C. Clark, D. Ortega, in: G.O. Phillips, D.J. Wedlock, P.A. Williams (Eds.), Gums and Stabilizers for the Food Industry, vol. 4 I.R.L. Press, 1988.

[23] C. Gaspar, I. Sousa, O. Laureano, Zeitschrift fur Lebensm. Unters. Forsch. 206 (1998) 169.

[24] K. Nakamura, K. Harada, Y. Tanaka, Food Hydrocolloids 5 (1993) 435.

[25] G. Sworn, G.R. Sanderson, W. Gibson, Food Hydrocolloids 4 (1995) 265.

[26] A.H. Clark, G.M. Kavanagh, S.B. Ross-Murphy, Food Hydrocolloids 15 (2001) 383.

[27] H.A. Barnes, A Handbook of Elementary Rheology, Institute of Non-Newtonian Fluid Mechanics, University of Wales, 2000.

[28] P.J. Carreau, Transactions of the Society of Rheology 16 (1972) 99 